\title{
Aluminous clay and pedogenic Fe oxides modulate aggregation and related carbon contents in soils of the humid tropics
}

\author{
Maximilian Kirsten ${ }^{1}$, Robert Mikutta ${ }^{2}$, Didas N. Kimaro ${ }^{3}$, Karl-Heinz Feger ${ }^{1}$, and Karsten Kalbitz ${ }^{1}$ \\ ${ }^{1}$ Institute of Soil Science and Site Ecology, Technische Universität Dresden, Tharandt, Germany \\ ${ }^{2}$ Soil Science and Soil Protection, Martin-Luther-Universität Halle-Wittenberg, Halle (Saale), Germany \\ ${ }^{3}$ Directorate of Research Innovations and Consultancy, Mwenge Catholic University, Moshi, Tanzania
}

Correspondence: Maximilian Kirsten (maximilian.kirsten@tu-dresden.de)

Received: 1 February 2021 - Discussion started: 26 February 2021

Revised: 21 May 2021 - Accepted: 6 June 2021 - Published: 6 July 2021

\begin{abstract}
Aggregation affects a wide range of physical and biogeochemical soil properties with positive effects on soil carbon storage. For weathered tropical soils, aluminous clays (kaolinite and gibbsite) and pedogenic $\mathrm{Fe}$ (oxyhydr)oxides (goethite and hematite; termed "Fe oxides") have been suggested as important building units for aggregates. However, as aluminosilicates, aluminum hydroxides, and Fe oxides are part of the clay-sized fraction it is hard to separate how certain mineral phases modulate aggregation. In addition, it is not known what consequences this will have for organic carbon (OC) persistence after land-use change. We selected topsoils with unique mineralogical compositions in the East Usambara Mountains of Tanzania under forest and cropland land uses, varying in contents of aluminous clay and Fe oxides. Across the mineralogical combinations, we determined the aggregate size distribution, aggregate stability, OC contents of aggregate size fractions, and changes in aggregation and OC contents under forest and cropland land use. Patterns in soil aggregation were rather similar across the different mineralogical combinations (high level of macroaggregation and high aggregate stability). Nevertheless, we found some statistically significant effects of aluminous clay and pedogenic Fe oxides on aggregation and $\mathrm{OC}$ storage. An aluminous clay content $>250 \mathrm{~g} \mathrm{~kg}^{-1}$ in combination with pedogenic $\mathrm{Fe}$ contents $<60 \mathrm{~g} \mathrm{~kg}^{-1}$ significantly promoted the formation of large macroaggregates $>4 \mathrm{~mm}$. In contrast, a pedogenic $\mathrm{Fe}$ content $>60 \mathrm{~g} \mathrm{~kg}^{-1}$ in combination with aluminous clay content of $<250 \mathrm{~g} \mathrm{~kg}^{-1}$ promoted OC storage and persistence even under agricultural use. The combination with low aluminous clay and high pedogenic Fe contents displayed the highest $\mathrm{OC}$ persistence, despite conversion of forest to cropland causing substantial disaggregation. This indicates that aggregation in these tropical soils is modulated by the mineralogical regime, causing moderate but significant differences in aggregate size distribution. Nevertheless, aggregation was little decisive for overall OC persistence in these highly weathered soils, where OC storage is more regulated by direct mineral-organic interactions.
\end{abstract}

\section{Introduction}

Many functions of soils such as food production, water purification, and climate regulation are tightly linked to soil structure (Bronick and Lal, 2005; FAO, 2015; Six et al., 2004). Aggregates are the structural backbone of soil, and changes in aggregation impact various processes such as root development, soil erosion, and soil organic carbon (OC) ac- cumulation (Chaplot et al., 2010; Le Bissonnais et al., 2018). Based on their size, soil aggregates are typically classified into small microaggregates $(<20 \mu \mathrm{m})$, large microaggregates $(20-250 \mu \mathrm{m})$, and macroaggregates $(>0.25 \mathrm{~mm})$ (Tisdall and Oades, 1982). Cementing agents such as clay minerals, metal (oxyhydr)oxides, and organic matter (OM) are considered as primary building units of microaggregates (Totsche et al., 2018), which provide the basis for the formation of larger 
soil structural units (Asano and Wagai, 2014). The study by Six et al. (2002) points to the special role of inorganic compounds such as clay minerals and pedogenic metal oxides in the formation of aggregates in the tropics. Pedogenic iron $\left(\mathrm{Fe}_{\mathrm{d}}\right)$ (oxyhydr)oxides (abbreviated as "Fe oxides") have been reported to facilitate macroaggregation (Peng et al., 2015) and aggregate stability (Duiker et al., 2003). Under the acidic conditions of weathered tropical soils, Fe oxides provide positively charged surfaces capable of reacting with negatively charged inorganic constituents, like clay minerals or OM (Kaiser and Guggenberger, 2003; Kleber et al., 2015; Six et al., 2004; Totsche et al., 2018). Aggregation might be ascribed to inorganic or organic cementing agents with no consensus about the relevance of each individual agent. Understanding the effects of individual cementing agents for aggregation is needed to disentangle their potential contribution to soil aggregation. For example, the extent of aggregation has been either positively related to the contents of clay and OC (Chaplot and Cooper, 2015; Paul et al., 2008; Spaccini et al., 2001) or to differences in the clay mineral composition (Fernández-Ugalde et al., 2013). Furthermore, Barthès et al. (2008) showed that texture had no effect on macroaggregation over a range of tropical soils characterized by lowactivity clay minerals. Such kinds of uncertainty may derive from the fact that the clay size particle fraction $(<2 \mu \mathrm{m})$ contains not only $\mathrm{OM}$ and different types of clay minerals but also variable contents of pedogenic $\mathrm{Fe}$ and aluminum $(\mathrm{Al})$ oxides (Barré et al., 2014; Fernández-Ugalde et al., 2013; Wagai and Mayer, 2007). Denef et al. (2004) showed that significant differences in the amount of microaggregates encased in macroaggregates can be related to the clay mineral composition $(2: 1$, mixed layer, $1: 1$ clays). They assume that interactions of $1: 1$ clay minerals with $\mathrm{Fe}$ oxides cause a higher aggregate stability compared to those involving $2: 1$ clay minerals (Denef et al., 2002, 2004). Such mutual interactions between typical aluminous clay-sized minerals (e.g., kaolinite, gibbsite) and pedogenic Fe oxides are thus possible drivers of aggregation in weathered tropical soils (Durn et al., 2019).

Soil aggregation is considered to be an important process that increases OC persistence because of the physical separation of OM from microorganisms and their exoenzymes (Six et al., 2004). Thus, improved aggregation could contribute to enhanced OC storage in soils (Kravchenko et al., 2015; Marín-Spiotta et al., 2008; Schmidt et al., 2011). Managing aggregation, e.g., for climate change mitigation, requires profound knowledge on the controls of aggregation and their effects on OC persistence (Paul et al., 2008). To the best of our knowledge, there are no studies available that have investigated the influence of changes in the content of clay minerals with low activity and the content of pedogenic metal oxides on aggregation under comparable mineralogical conditions for weathered tropical soils. Macroaggregates are particularly susceptible to soil management (Six et al., 2000a; Totsche et al., 2018). Consequently, destruction of macroag- gregates upon changes from forests to cropland might account for OC losses that were observed in tropical soils (Don et al., 2011; Kirsten et al., 2019; Mujuru et al., 2013). The stability of aggregates should thus determine OC losses induced by land-use change, and higher losses should be related to lower aggregate stability (Denef et al., 2002; Le Bissonnais et al., 2018; Six et al., 2000b). We are currently not aware of any studies that solve the puzzle to which extent the amount of aluminous clay and pedogenic $\mathrm{Fe}$ oxides controls soil aggregation and OC storage in highly weathered soils of the humid tropics.

This study takes advantage of soils under natural forest and cropland in the East Usambara Mountains of Tanzania. The mineralogical composition of the study soils is very homogeneous with kaolinite and gibbsite as the main aluminous minerals of the clay fraction and goethite and hematite as dominant pedogenic Fe oxides (Kirsten et al., 2021). Yet, the ratio of aluminous clays to $\mathrm{Fe}$ oxides differed strongly, giving rise to unique mineralogical combinations under both land use types. Thus, the conversion of natural forest to cropland in the study region enables us to evaluate the effect of land-use change under each mineralogical combination on soil physical properties and related OC persistence. In the precursor study, we found a positive relationship between the storage of mineral-associated $\mathrm{OC}$ and the ratio of pedogenic Fe to aluminous clay under forest and cropland land use, suggesting that a larger share of Fe oxides is linked to larger OC storage and persistency against land-use change (Kirsten et al., 2021). In the present study, we test whether aggregation and its contribution to OC storage follow similar patterns or are decoupled from the individual contribution of main mineral constituents. In detail, our main research goal was to investigate the individual role of aluminous clay and pedogenic $\mathrm{Fe}$ oxides for determining (i) the soil aggregate size distribution, (ii) aggregate stability, (iii) the consequences for OC allocation into different aggregate size fractions, and (iv) the consequences for $\mathrm{OC}$ persistence related to land-use change. We hypothesize that the mineralogical combination resulting in the largest aggregate stability also results in the largest OC persistence. For this purpose, we determined the aggregate size distribution of soils under both land uses, determined the OC contents of obtained aggregate fractions, and tested the stability of the two largest aggregate size fractions (2-4 and $>4 \mathrm{~mm}$ ). As a measure of OC persistence, the OC content of aggregate size fractions was compared between the two land uses in the same mineralogical combination. We generally focused on soil samples from $0-10 \mathrm{~cm}$ to test our current hypothesis since land-use-induced OC losses from soils of the study region largely occur in this depth increment (Kirsten et al., 2019). 


\section{Material and methods}

\subsection{Study area and soil sampling}

The study was conducted in the Eastern Usambara Mountains of Tanzania close to the village Amani $\left(5^{\circ} 06^{\prime} 00^{\prime \prime} \mathrm{S}\right.$, $38^{\circ} 38^{\prime} 00^{\prime \prime} \mathrm{E}$ ). The climate is humid monsoonal with a mean annual precipitation of $1918 \mathrm{~mm}$ and a mean annual temperature of $20.6^{\circ} \mathrm{C}$ with low variability within the study area (Hamilton and Bensted-Smith, 1989). The dominating Acrisols and Alisols, developed from Precambrian crystalline bedrock, are deeply weathered and highly leached, with visible clay illuviation in the subsoil (Kirsten et al., 2019). Briefly, all soil samples were collected on mid-slope position. We sampled six plots under forest and three under annual cropping. The site selection was done based on total clay amount determined in the field and the associated total Fe amount measured with a portable XRF device (Kirsten et al., 2021). We did not observe systematic differences in vegetation composition of the forest sites, and NMR spectra showed a similar composition of litter for each of the two land uses investigated (Kirsten et al., 2021) . Furthermore, several visits in the study region over the last decade (2012, 2013, 2015, and 2018) combined with personal talks to farmers and local partners working in the region enabled us to select cropland sites with similar agricultural management (cultivation of cassava (Manihot esculenta), hand hoe tillage, biomass burning before seed bed preparation). At each plot, mineral soil from three adjacent and randomly distributed soil pits at mid-slope position was sampled at $0-5$ and 5$10 \mathrm{~cm}$ depths. This procedure was chosen because we identified two soil horizons at $0-5$ and $5-10 \mathrm{~cm}$ depth based on differences in color and structure. To have a consistent sampling design, we applied this distinction to the cropland sites, too. Living roots were removed and aliquots of the soils were sieved to $<2 \mathrm{~mm}$ after drying at $40^{\circ} \mathrm{C}$. For each depth increment, three undisturbed soil cores $\left(100 \mathrm{~cm}^{3}\right)$ were collected for bulk density determination.

\subsection{Soil analyses}

\subsubsection{Basic soil properties and selected mineralogical combinations}

Bulk density was determined after drying the soil at $105^{\circ} \mathrm{C}$ and corrected for coarse fragments (Carter and Gregorich, 2008). Soil $\mathrm{pH}$ was measured in $0.01 \mathrm{MCaCl}_{2}$ at a soil to solution ratio of $1: 2.5$. Extraction of poorly crystalline $\mathrm{Fe}$ and $\mathrm{Al}$ phases as well as of $\mathrm{Fe}$ and $\mathrm{Al}$ complexed by $\mathrm{OM}$ was done with ammonium oxalate according to Schwertmann (1964). Effective cation exchange capacity $\left(\mathrm{CEC}_{\text {eff }}\right)$ and base saturation (BS) were determined following the procedure provided by Trüby and Aldinger (1989). Contents of $\mathrm{OC}$ and total $\mathrm{N}$ were analyzed by hightemperature combustion at $950^{\circ} \mathrm{C}$ and thermo-conductivity detection (Vario EL III/Elementar, Heraeus, Langenselbold,
Germany). A combined dithionite-citrate-bicarbonate extraction and subsequent texture analysis was applied to determine the contents of aluminous clay and total pedogenic $\mathrm{Fe}\left(\mathrm{Fe}_{\mathrm{d}}\right)$. Briefly, 5-6g of soil pre-treated with $30 \% \mathrm{H}_{2} \mathrm{O}_{2}$ was extracted with $30 \mathrm{~g}$ of sodium dithionite $\left(\mathrm{Na}_{2} \mathrm{~S}_{2} \mathrm{O}_{4}\right)$ and $1.35 \mathrm{~L}$ of buffer solution $(0.27 \mathrm{M}$ trisodium citrate dihydrate $\left(\mathrm{C}_{6} \mathrm{H}_{5} \mathrm{Na}_{3} \mathrm{O}_{7} \cdot 2 \mathrm{H}_{2} \mathrm{O}\right)+0.11 \mathrm{M}$ sodium bicarbonate $\left.\left(\mathrm{NaHCO}_{3}\right)\right)$ at $75^{\circ} \mathrm{C}$ in a water bath for $15 \mathrm{~min}$ (Mehra and Jackson, 1958). The Fe concentration of the extracts were measured by inductively coupled plasma optical emission spectroscopy (ICP-OES) using a CIROS-CCD instrument (Spectro, Kleve, Germany). The residues of the extraction were then subjected to a texture analysis using the pipette method (Gee and Bauder, 1986). Details of the procedure are described in Kirsten et al. (2021). Based on the respective content of aluminous clay and pedogenic Fe oxide in the 5$10 \mathrm{~cm}$ depth increment, each sample was assigned to a certain mineralogical combination. The threshold values for aluminous clay and pedogenic Fe to distinguish between "high" and "low" were set to 250 and $60 \mathrm{~g} \mathrm{~kg}^{-1}$, respectively. We differentiated four groups varying in contents of aluminous clay and pedogenic Fe oxides under forest (i.e., "low claylow Fe", "low clay-high Fe", "high clay-low Fe", "high clay-high Fe"), and three analogous groups under cropland (i.e., "low clay-low Fe", "low clay-high Fe", "high clayhigh Fe"). Using the threshold criterion for assigning the individual samples to a mineralogical combination resulted in an unequal number of repetitions for combinations under forests $(n=3-7)$, whereas those under cropland remained the same $(n=3)$.

\subsubsection{Aggregate size distribution, aggregate stability, and carbon contents}

Aggregate size distribution was determined by dry sieving as it most closely resembles soil conditions at the end of the long dry season. Undisturbed soil was dried at $40{ }^{\circ} \mathrm{C}$ for $48 \mathrm{~h}$. Separation of aggregate sizes was conducted with a sieving machine (AS 200 control "g", Retsch, Hanau, Germany) combined with a set of four sieves with meshes of 4 , 2,1 , and $0.25 \mathrm{~mm}$, respectively (Larney, 2008). The amplitude was set to $1.51 \mathrm{~mm}$ (7.6 $\mathrm{g}$ force), which was applied over a sieving duration of $3 \mathrm{~min}$. Aggregate stability was tested for the two largest aggregate size fractions $(2-4 \mathrm{~mm}$ and $>4 \mathrm{~mm}$ ). The fast-wetting pretreatment was applied to both fractions (Le Bissonnais, 1996) using a wet-sieving apparatus (Eijkelkamp, Giesbeek, the Netherlands) with sieve openings of $63 \mu \mathrm{m}$. This procedure simulates the transition of aggregates from dry to rainy season. Sieving was conducted in ethanol for $3 \mathrm{~min}$ (stroke $1.3 \mathrm{~cm}, f=34 \mathrm{~min}^{-1}$ ). All aggregates remaining on the sieve were dried at $105^{\circ} \mathrm{C}$. Water-stable aggregates were subsequently introduced to a sieving apparatus with a set of five sieves with mesh sizes of $4,2,1,0.63$, and $0.25 \mathrm{~mm}$, respectively (Larney, 2008). For each obtained aggregate fraction by dry sieving, OC contents 
were analyzed by high-temperature combustion at $950{ }^{\circ} \mathrm{C}$ and thermo-conductivity detection (Vario EL III/Elementar, Heraeus, Langenselbold, Germany). The mass-corrected OC content of a certain aggregate fraction was calculated using Eq. (1) to resemble the contribution to total soil OC:

$$
\text { Mass-corrected } \mathrm{OC}_{\text {Aggregate }}=\frac{m_{i}}{\sum_{i=0}^{n} m_{i}} \times \mathrm{OC}_{\text {Aggregate }}
$$

where $m_{i}$ represents the mass of an aggregate size fraction $(\mathrm{g}), \sum m_{i}$, the sum of masses of all size fractions $(\mathrm{g})$, and $\mathrm{OC}_{\text {Aggregate }}$ the OC content of aggregate fraction " $i$ ".

The mean weight diameter (MWD) of aggregates was calculated using Eq. (2) for undisturbed soil to describe the initial aggregate size distribution and for the large aggregate size fractions after exposure to the stability test to evaluate the effect of fast wetting on aggregate stability:

$\mathrm{MWD}=\sum_{i=0}^{n} \frac{m_{i}}{\sum m_{i}} \times d_{i}$,

where $m_{i}$ represents the mass of an aggregate size fraction $(\mathrm{g}), \sum m_{i}$ the sum of masses of all size fractions $(\mathrm{g})$, and $d_{i}$ the mean mesh diameter of fraction " $i$ " (mm). The MWD of the aggregate fraction $>4 \mathrm{~mm}$ was estimated by doubling the largest sieve size diameter (Youker and McGuinness, 1957).

\subsection{Statistics and calculations}

The mean and standard deviation of data were calculated with the software package $\mathrm{R}$ (version 3.6.0). To test for significant differences between mineralogical combinations, land uses, and depths, we applied the linear model function $[\operatorname{lm}()]$ in combination with analysis of variance $[\operatorname{aov}(\operatorname{lm}()]$. The Tukey HSD test was used as a post hoc comparison of means; the LSD test was applied in the case of nonequality of variances. Regression analysis was used to test for relationships between mineralogical properties and MWD, masses of aggregate size fractions, aggregate stability, and OC losses due to land-use change. Statistical differences are reported at a significance level of $p<0.05$. Based on our selected threshold values for aluminous clay and pedogenic Fe oxides, we were able to achieve the following number of replicates for the mineralogical combinations: "low clay-low Fe" under forest $(n=4)$, "low clay-high Fe" under forest $(n=4)$, "high clay-low Fe" under forest $(n=3)$, and "high clay-high Fe" under forest $(n=7)$, with all cropland combinations $(n=3)$.

\section{Results}

\subsection{Mineralogical composition and general soil properties}

The selected mineralogical combinations represent a broad spectrum of possible combination of mineral aluminous clay and Fe oxide constituents. Amounts of aluminous clay varied between 149 and $438 \mathrm{~g} \mathrm{~kg}^{-1}$ and $\mathrm{Fe}_{\mathrm{d}}$ between 21 and $101 \mathrm{~g} \mathrm{~kg}^{-1}$ across all sites and land uses. Amorphous $\mathrm{Fe}$ and $\mathrm{Al}$ phases contributed little to pedogenic oxides as indicated by low proportions of oxalate-extractable $\mathrm{Fe}$ and $\mathrm{Al}$ (Table 1). The advanced weathering state of study soils was also reflected in low $\mathrm{pH}$ and $\mathrm{CEC}_{\text {eff values (Table 1). }}$

\subsection{Influence of aluminous clay and pedogenic Fe on aggregate size distribution}

\subsubsection{Mean weight diameter}

The studied soils were highly aggregated and showed significant variation in their aggregate size distribution across the mineralogical combinations (Fig. 1a, Table 2). The low clay-low Fe combination under forest displayed the significantly smallest MWD (e.g., $2.9 \mathrm{~mm}$ in $0-5 \mathrm{~cm}$ depth; Table 2). In contrast, the low clay-high Fe combination always had the largest MWD (e.g., $4.8 \mathrm{~mm}$ in 0-5 cm depth; Table 2) among the other forest combinations. Our data suggest that the MWD under forest is significantly positively influenced by the $\mathrm{Fe}_{\mathrm{d}}$ content (e.g., MWD Forest $0-5 \mathrm{~cm}: r^{2}=0.40, p<$ 0.001; Table S1), whereas nearly no effect was observed for aluminous clay. Contrary to the mineralogical combinations under forest, the significantly smallest MWD under cropland was within the low clay-high Fe combination $(2.7 \mathrm{~mm}$ in both depths; Table 2). The low clay-low Fe and high clayhigh Fe cropland combinations showed no strong differences in their MWDs. Nonetheless, a significant negative linear relationship existed between MWD and the ratio of pedogenic Fe to aluminous clay $\left(\mathrm{MWD}_{\text {Cropland } 0-5 \mathrm{~cm}}: r^{2}=0.47\right.$, $p=0.03$; MWD Cropland 5-10 cm: $r^{2}=0.47, p=0.02$ ) for the mineralogical combinations under cropland (Table $\mathrm{S} 1$ in the Supplement).

\subsubsection{Macroaggregates $>4$ and $2-4 \mathrm{~mm}$}

Corresponding to the smallest MWD, the low clay-low $\mathrm{Fe}$ forest combination contained the smallest fraction of $>4 \mathrm{~mm}$ aggregates. The contribution of these large aggregates under forest increased in the following order: low clay-low $\mathrm{Fe}<$ low clay-high $\mathrm{Fe}=$ high clay-high $\mathrm{Fe}<$ high clay-low Fe (Fig. 1a). For croplands, the low clay-high Fe combination comprised the smallest amount of $>4 \mathrm{~mm}$ aggregates, whereas the high clay-high Fe combination exhibited the respective highest share (Fig. 1a). The explained variance of $>4 \mathrm{~mm}$ aggregate mass by aluminous clay and $\mathrm{Fe}_{\mathrm{d}}$ was generally low, except for the cropland combinations (positive effect of aluminous clay and negative effect of pedogenic $\mathrm{Fe}$; Table S1).

The mineralogical combinations affected the amounts of 2-4 $\mathrm{mm}$ aggregates differently than those of $>4 \mathrm{~mm}$ aggregates. The low clay-high Fe combination under forest and cropland contained slightly but significantly more 2-4 mm aggregates (Fig. 1a), being associated with a significantly 


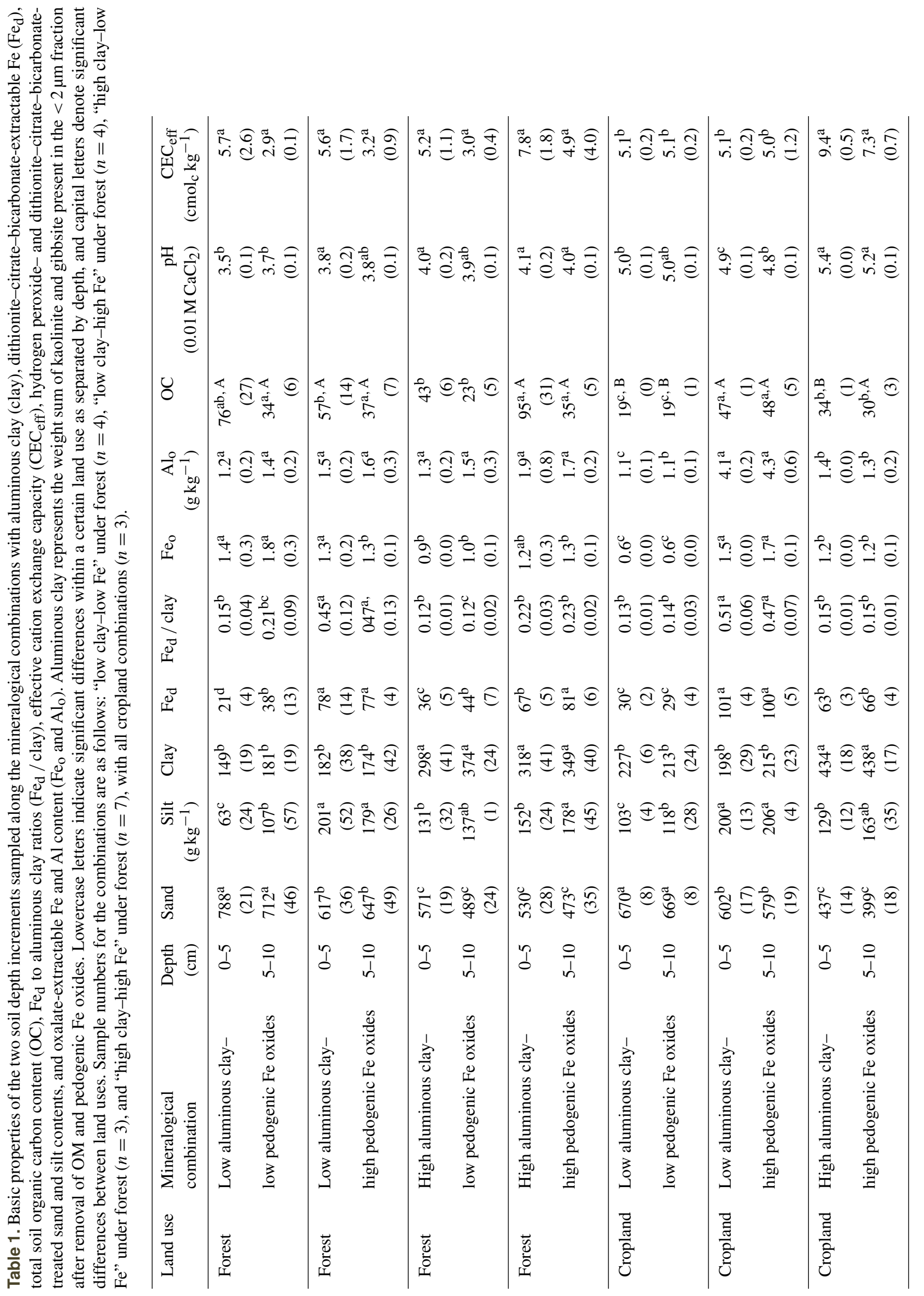



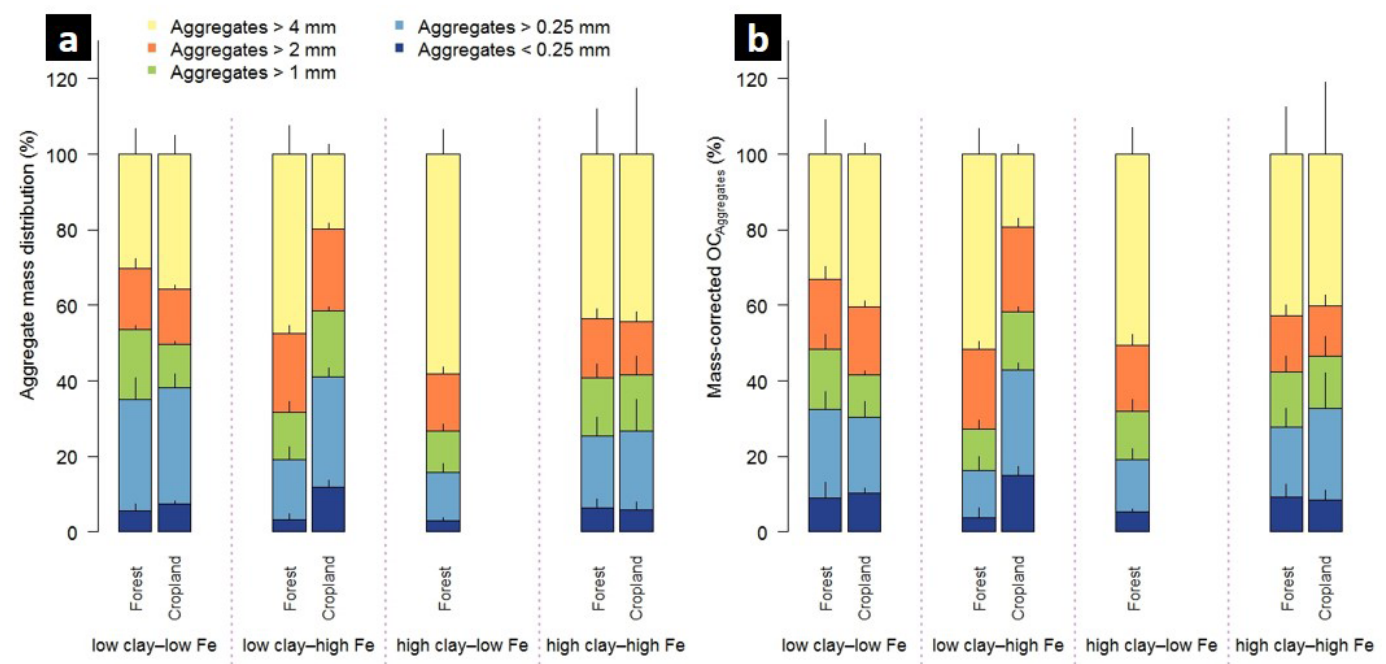

Figure 1. Aggregate size distribution of the combined 0-5 and 5-10 cm depth increments (a) and relative mass-corrected OC contents (b) along the mineralogical combinations. Clay represents the weight sum of kaolinite and gibbsite present in the $<2 \mu \mathrm{m}$ fraction after removal of $\mathrm{OM}$ and pedogenic Fe oxides, and Fe denotes the content of pedogenic Fe oxides extracted with dithionite-citrate-bicarbonate. Sample numbers for the combinations are as follows: "low clay-low Fe" under forest $(n=4)$, "low clay-high Fe" under forest $(n=4)$, "high claylow Fe" under forest $(n=3)$, and "high clay-high Fe" under forest $(n=7)$, with all cropland combinations $(n=3)$.

higher $\mathrm{Fe}_{\mathrm{d}}$ to aluminous clay ratio (Table 1). In fact, in a multiple regression model for the entire data set (combined land uses and depths), we observed a positive relationship between the mass of $2-4 \mathrm{~mm}$ aggregates and $\mathrm{Fe}_{\mathrm{d}}$ content, whereas the content of aluminous clay had a negative effect $\left(r^{2}=0.57, p<0.001\right.$; Table S1).

\subsubsection{Microaggregates $<0.25 \mathrm{~mm}$}

Across all mineralogical combinations, amounts of $<0.25 \mathrm{~mm}$ aggregates were principally similar, despite the significantly higher shares in the low clay-low Fe and high clay-high $\mathrm{Fe}$ combinations under forest. A significantly larger amount of $<0.25 \mathrm{~mm}$ aggregates was observed in the low clay-high $\mathrm{Fe}$ combination under cropland. In this mineralogical combination, land-use change caused a quadrupling of $<0.25 \mathrm{~mm}$ aggregate mass from about 30 to nearly $120 \mathrm{~g} \mathrm{~kg}^{-1}$ (Table 2). In contrast to the macroaggregate fractions shown above, there was no correlation between mineralogical parameters and the mass of $<0.25 \mathrm{~mm}$ aggregates, neither for the entire data set (combined land uses and depths) nor when separated by soil depth (Table S1).

In summary, mineralogical combinations and land use significantly affected the aggregate size distribution of soils, despite the fact that quantitative relations to mineralogical proxies could not be observed for each aggregate class. In undisturbed forest soils, higher pedogenic Fe contents resulted in increasing MWD especially in $0-5 \mathrm{~cm}$ depth and significantly larger amounts of $>2 \mathrm{~mm}$ aggregates. The conversion from forest to croplands either decreased MWD, as particularly observed for the low clay-high Fe combination, or had no effect (low clay-low Fe). Overall, the observed differences in aggregate masses and MWD were surprisingly moderate, given the widely differing contents in aluminous clay and $\mathrm{Fe}$ oxides across the mineralogical combinations.

\subsection{Aggregate stability}

In general, there was little variation of MWD values for $>4 \mathrm{~mm}$ aggregates over all mineralogical combinations. In fact, the MWD of this fraction was always close to its calculated mean diameter $(6 \mathrm{~mm}$; calculation was done after; Youker and McGuinness, 1957), overall indicating a high stability. Nevertheless, there were some minor differences in aggregate stability across mineralogical combinations. The low clay-low Fe and high clay-low Fe combinations had a significantly lower aggregate stability in comparison with the two other combinations under the two land uses (Table 3). The slightly higher abundance of $2-4 \mathrm{~mm}$ aggregates in the low clay-high Fe combination under forest and cropland was accompanied by a significantly higher aggregate stability under both land uses (Tables 2 and 3). In summary, all aggregates can be classified as stable with only minor differences imposed by the mineralogical combinations. Slightly higher aggregate stability was associated with a larger amount of pedogenic $\mathrm{Fe}$, and increasing $\mathrm{Fe}_{\mathrm{d}}$ to aluminous clay ratios, whereas differences in the amount of aluminous clay had almost no effect on the aggregate stability (Table S2).

\subsection{Organic carbon in soils and aggregate size fractions}

In the entire data set, variation in mineral constituents caused pronounced differences in the OC content of the soils be- 


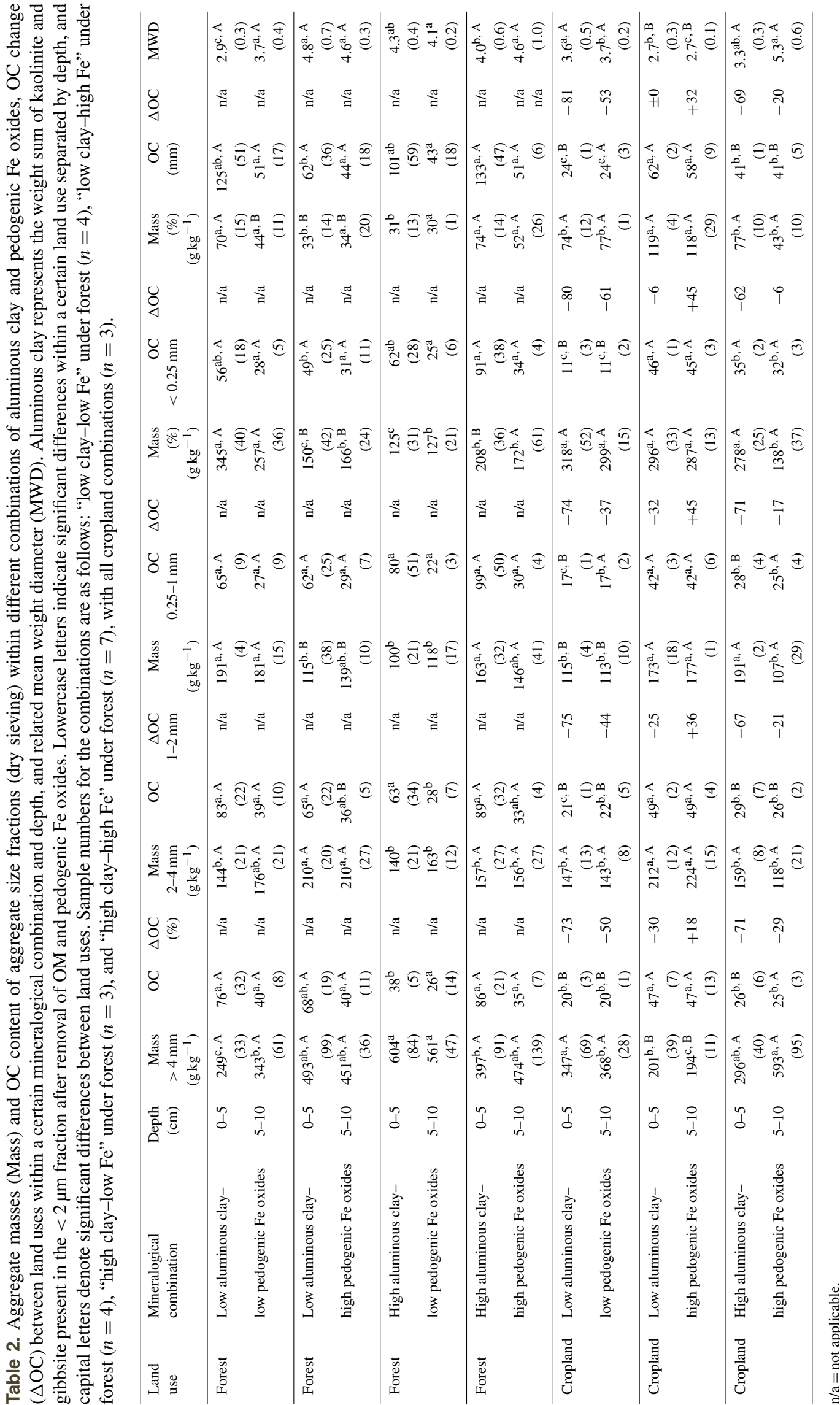


Table 3. Aggregate stability of selected aggregate size fractions after applying the fast-wetting procedure along the different combinations of aluminous clay and pedogenic Fe oxides, indicated by the resulting mean weight diameter (MWD). Aluminous clay represents the weight sum of kaolinite and gibbsite present in the $<2 \mu \mathrm{m}$ fraction after removal of OM and pedogenic Fe oxides. Lowercase letters indicate significant differences within a certain land use separated by depth, and capital letters denote significant differences between land uses. Sample numbers for the combinations are as follows: "low clay-low Fe" under forest $(n=4)$, "low clay-high Fe" under forest $(n=4)$, "high clay-low Fe" under forest $(n=3)$, and "high clay-high Fe" under forest $(n=7)$, with all cropland combinations $(n=3)$.

\begin{tabular}{llrrr}
\hline \multirow{2}{*}{ Land } & Mineralogical & Depth & \multicolumn{2}{c}{ MWD $(\mathrm{mm})$} \\
\cline { 4 - 5 } & combination & $(\mathrm{cm})$ & Fast wetting & Fast wetting \\
& & & $4 \mathrm{~mm}$ & $2-4 \mathrm{~mm}$ \\
\hline \multirow{2}{*}{ Forest } & Low aluminous clay- & $0-5$ & $4.9^{\mathrm{b}, \mathrm{A}}(0.4)$ & $2.6^{\mathrm{b}, \mathrm{A}}(0.1)$ \\
& low pedogenic Fe oxides & $5-10$ & $5.1^{\mathrm{a}, \mathrm{A}}(0.3)$ & $2.4^{\mathrm{b}, \mathrm{A}}(0.3)$ \\
\hline \multirow{2}{*}{ Forest } & Low aluminous clay- & $0-5$ & $5.6^{\mathrm{a}, \mathrm{A}}(0.2)$ & $2.8^{\mathrm{a}, \mathrm{A}}(0.1)$ \\
& high pedogenic Fe oxides & $5-10$ & $4.9^{\mathrm{a}, \mathrm{A}}(0.9)$ & $2.7^{\mathrm{a}, \mathrm{A}}(0.1)$ \\
\hline \multirow{2}{*}{ Forest } & High aluminous clay- & $0-5$ & $5.4^{\mathrm{ab}}(0.4)$ & $2.7^{\mathrm{b}}(0.0)$ \\
& low pedogenic Fe oxides & $5-10$ & $4.5^{\mathrm{a}}(1.2)$ & $2.4^{\mathrm{b}}(0.3)$ \\
\hline \multirow{2}{*}{ Forest } & High aluminous clay- & $0-5$ & $5.5^{\mathrm{a}, \mathrm{A}}(0.2)$ & $2.6^{\mathrm{b}, \mathrm{A}}(0.1)$ \\
& high pedogenic Fe oxides & $5-10$ & $5.2^{\mathrm{a}, \mathrm{A}}(0.4)$ & $2.6^{\mathrm{ab}, \mathrm{B}}(0.1)$ \\
\hline \multirow{2}{*}{ Cropland } & Low aluminous clay- & $0-5$ & $4.4^{\mathrm{b}, \mathrm{A}}(0.1)$ & $2.6^{\mathrm{c}, \mathrm{A}}(0.0)$ \\
& low pedogenic Fe oxides & $5-10$ & $4.9^{\mathrm{b}, \mathrm{A}}(0.3)$ & $2.4^{\mathrm{b}, \mathrm{A}}(0.1)$ \\
\hline \multirow{2}{*}{ Cropland } & Low aluminous clay- & $0-5$ & $5.2^{\mathrm{a}, \mathrm{A}}(0.2)$ & $2.9^{\mathrm{a}, \mathrm{A}}(0.0)$ \\
& high pedogenic Fe oxides & $5-10$ & $5.3^{\mathrm{ab}, \mathrm{A}}(0.1)$ & $2.8^{\mathrm{a}, \mathrm{A}}(0.0)$ \\
\hline \multirow{2}{*}{ Cropland } & High aluminous clay- & $0-5$ & $4.9^{\mathrm{a}, \mathrm{B}}(0.2)$ & $2.7^{\mathrm{b}, \mathrm{A}}(0.1)$ \\
& high pedogenic Fe oxides & $5-10$ & $5.6^{\mathrm{a}, \mathrm{A}}(0.2)$ & $2.8^{\mathrm{a}, \mathrm{A}}(0.0)$ \\
\hline \multirow{2}{*}{} & & & &
\end{tabular}

tween 19 to $95 \mathrm{~g} \mathrm{OC} \mathrm{kg}^{-1}$ (Table 1). A significant proportion of the total OC content of all forest soils was present in $>4 \mathrm{~mm}$ aggregates in both depth increments (low claylow Fe: $33 \%<$ high clay-high Fe: $43 \%<$ high clay-low Fe: $51 \%<$ low clay-high Fe: $52 \%$; Fig. 1b). Forest to cropland conversion caused OC losses from most aggregate size fractions (Fig. 2). For the $>4 \mathrm{~mm}$ aggregates this was significantly modified by the mineralogical combinations at least at $0-5 \mathrm{~cm}$ depth, generally following the order low clayhigh $\mathrm{Fe}<$ high clay-high Fe $<$ low clay-low Fe (Table S3). Losses of OC from aggregate size fractions were generally higher at $0-5$ than at $5-10 \mathrm{~cm}$ depth (Fig. 2). As mentioned above, no significant loss of total OC occurred for the low clay-high Fe combination, irrespective of the significant mass redistribution of the $>4 \mathrm{~mm}$ aggregate fraction into smaller aggregate fractions (Table 2). Although there were differences in OC losses among mineralogical combinations, there was little indication that coarser aggregate size fractions lost more OC than smaller ones (Table 2).

\section{Discussion}

The aggregate size distribution of soils along the mineralogical combinations under both land uses was in the range of values reported for African soils. For example, soils with strongly contrasting clay content (220 and $650 \mathrm{~g} \mathrm{~kg}^{-1}$ ) but similar clay mineralogy (kaolinite) in the central highlands of Kenya displayed macroaggregate contents of 245 and $636 \mathrm{~g} \mathrm{~kg}^{-1}$ soil, respectively (Gentile et al., 2010). In addition, for soils from the catchment of the Ruiru river, also located in the central highlands of Kenya, it was shown that macroaggregates $(2-4.2 \mathrm{~mm}$ ) displayed a large stability (Kamamia et al., 2021). The reported MWDs after application of the fast-wetting stability test were $2.5 \mathrm{~mm}$ for cropland and $3.2 \mathrm{~mm}$ for indigenous forest sites (Kamamia et al., 2021). These values are close to those observed in our study soils for 2-4 mm aggregates. In contrast, soils in Brazil under native forest vegetation and similar mineral composition (kaolinite, gibbsite, hematite) even subsumed over $90 \%$ of total aggregate mass in $>2 \mathrm{~mm}$ aggregates (Maltoni et al., 2017). Nonetheless, reported data all point at a better soil structure and aggregate stability of tropical soils dominated by low-activity clay minerals and well-crystalline Fe oxides, which is consistent with all mineralogical combinations of this study. 


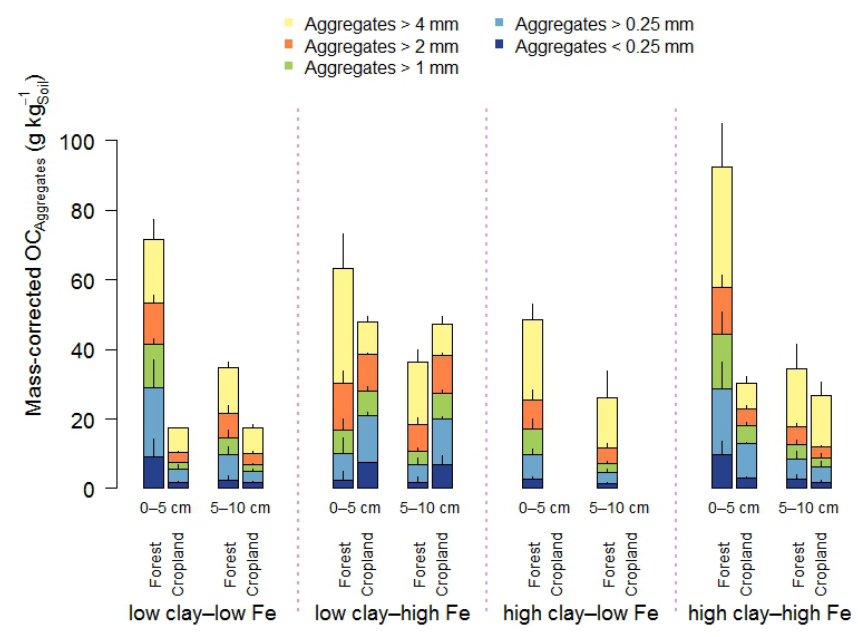

Figure 2. Mass-corrected OC contents of aggregate size fractions along the mineralogical combinations. Clay represents the weight sum of kaolinite and gibbsite present in the $<2 \mu \mathrm{m}$ fraction after removal of $\mathrm{OM}$ and pedogenic $\mathrm{Fe}$ oxides, and $\mathrm{Fe}$ denotes the content of pedogenic $\mathrm{Fe}$ oxides extracted with dithionite-citratebicarbonate. Sample numbers for the combinations are as follows: "low clay-low Fe" under forest $(n=4)$, "low clay-high Fe" under forest $(n=4)$, "high clay-low Fe" under forest $(n=3)$, and "high clay-high Fe" under forest $(n=7)$, with all cropland combinations $(n=3)$.

\subsection{Aggregation and aggregate stability as controlled by aluminous clay and pedogenic Fe oxides}

Our data demonstrate relatively small differences in aggregation among the generally well-aggregated study soils, being characterized by high aggregate stability despite large variations in aluminous clay (factor of 3 ) and pedogenic Fe (factor of 5) contents. Yet, we noticed some distinct modifications of the aggregation size distribution and aggregate stability in both forest and cropland soils.

\subsubsection{Mineralogical control on the formation of large macroaggregates}

The low clay-low $\mathrm{Fe}$ soil under forest had a significantly smaller amount of $>4$ and 2-4 mm aggregates and a significantly lower MWD than all other mineralogical combinations. Notably, a combined increase in aluminous clay and Fe oxides did not necessarily cause a shift towards larger aggregates and thus higher MWD (see low clay-high Fe forest). Furthermore, the low clay-low $\mathrm{Fe}$ and high clay-high $\mathrm{Fe}$ combinations under forest contained more $<0.25 \mathrm{~mm}$ aggregates. Thus, under undisturbed soil conditions it appears that the formation of larger aggregates is promoted if one of the two aggregate-forming mineral fractions is more abundant than the other (high clay-low Fe and low clay-high Fe combinations).
We assume that the positive effect of increasing aluminous clay content on the aggregate mass $>4 \mathrm{~mm}$ is related to the hybrid electrostatic properties of kaolinite on edges (variable) and surfaces (permanent negative), which enable the formation of characteristic house-of-cards structures (Qafoku and Sumner, 2002). In addition to this increase in aggregation caused by the dominance in kaolinitic properties (i.e., high clay-low $\mathrm{Fe}$ ), we also expect that, similar to the study by Dultz et al. (2019), there are mixing ratios between aluminous clay and pedogenic Fe minerals, which lead to improved aggregation (greater MWD; i.e., low clay-high $\mathrm{Fe})$. This effect is probably explained by changes in the electrostatic properties of the mineralogical combinations, as was shown in the study by Hou et al. (2007) for kaolinite in different relative combinations with goethite and hematite. Nevertheless, aluminous clay is the decisive control for macroaggregation in these weathered tropical soils, confirming the often-described promoting effect of increasing clay content on aggregation (Feller and Beare, 1997). This is in line with results from two Oxisols in Brazil (Vrdoljak and Sposito, 2002), showing kaolinite being the backbone of macroaggregates.

Consequently, the dominant role of pedogenic Fe oxides for macroaggregation under undisturbed tropical soil conditions proposed by Six et al. (2002) cannot be confirmed in our study. This is also supported by the low clay-high Fe forest soil, which contained a smaller amount of $>4 \mathrm{~mm}$ aggregates compared to the high clay-low Fe forest soil in both depth increments. Furthermore, the high clay-low Fe and high clay-high $\mathrm{Fe}$ combinations under forest also nicely demonstrate how nearly equal amounts of aluminous clay plus pedogenic $\mathrm{Fe}$ oxides (i.e., similar clay contents) cause different amounts of $>4 \mathrm{~mm}$ aggregates. Consequently, the connection between textural properties and aggregation can remain hidden (Barthès et al., 2008) without considering the mineralogical composition of the whole clay fraction (Fernández-Ugalde et al., 2013; King et al., 2019; West et al., 2004).

In contrast to the $>4 \mathrm{~mm}$ aggregates, $2-4 \mathrm{~mm}$ aggregates corresponded more clearly to the positive effect of pedogenic Fe oxides on aggregation and aggregate stability as proposed for weathered tropical soils (Igwe et al., 2013; Peng et al., 2015; Six et al., 2002). Both the low clay-high Fe forest and low clay-high $\mathrm{Fe}$ cropland soils contained somewhat but significantly more $2-4 \mathrm{~mm}$ aggregates than other mineral combinations in concert with a higher aggregate stability of this particular fraction. This finding also demonstrates that mineral interactions forming water-stable aggregates in tropical soils are differently affected by a given mineralogical combination. Higher $\mathrm{Fe}_{\mathrm{d}}$ to aluminous clay ratios $(>0.45)$ modulate aggregate distribution towards aggregates $2-4 \mathrm{~mm}$, whereas distinctly lower values (high clay-low Fe forest: 0.12 ) shifted the maximum to $>4 \mathrm{~mm}$ aggregates.

Overall, the two macroaggregate fractions discussed above are differentially affected by the mineralogical combinations, 
although the magnitude was less than expected, given the pronounced variation in aluminous clay and Fe contents.

\subsubsection{Land use impact on aggregation within mineral combinations - implications for aggregate stability}

Land-use change had a distinct impact on aggregate distribution like indicated in other studies (Feller and Beare, 1997; Six et al., 2002) and depended also on the mineralogical combinations, though croplands did not follow the trajectory observed under forest. A significantly lower MWD under low clay-high Fe rather than low clay-low Fe can be mainly attributed to a reduced amount of $>4 \mathrm{~mm}$ aggregates. We assume that differences in the ratio of pedogenic Fe to aluminous clay in the low clay-low $\mathrm{Fe}$ and high clay-high $\mathrm{Fe}$ (0.13 to 0.15 ) in comparison with the low clay-high Fe combination $(0.47$ to 0.51$)$ under cropland explain the stability of "house-of-cards" structures like described for mineralogically similar Oxisols from Brazil and India (Bartoli et al., 1992). Accordingly, a higher $\mathrm{Fe}_{\mathrm{d}}$ to aluminous clay ratios seems to be disadvantageous for the formation and stability of such structures, especially in $>4 \mathrm{~mm}$ aggregates. The different $\mathrm{pH}$-dependent charge characteristics of kaolinite and pedogenic Fe oxides (Kaiser and Guggenberger, 2003) and their relative share can lead to altered charge properties of soils (Anda et al., 2008). We hypothesize that an increasing amount of $\mathrm{Fe}$ oxides adds more positive charge, thus possibly reducing structural integrity and aggregate stability if not sufficiently compensated by OM or clay minerals. Furthermore, in the low clay-high Fe cropland combination, landuse change caused a significant 4-fold increase of $<0.25 \mathrm{~mm}$ aggregates due to the breakdown of $>4 \mathrm{~mm}$ aggregates.

The less intense formation of $>4 \mathrm{~mm}$ aggregates in the low clay-high Fe forest combination was also observed under cropland, whereas the low clay-low Fe and high clayhigh Fe croplands showed either no significant decrease or even an increase in $>4 \mathrm{~mm}$ aggregate mass. Thus, simultaneous abundance of large amounts of aluminous clay and pedogenic $\mathrm{Fe}$ oxides preserved a higher aggregate stability than under mineralogically imbalanced conditions, although no conclusions can be drawn for the high clay-low Fe combination. Nonetheless, $>4 \mathrm{~mm}$ aggregates had a higher resistance to field operations in mineralogical combinations with lower $\mathrm{Fe}_{\mathrm{d}}$ to aluminous clay ratios $(0.13$ to 0.15$)$. Nonetheless, our results show that agricultural management does not necessarily decrease macroaggregation and related MWDs, like reported in Rabbi et al. (2015).

\subsection{Importance of aggregation for OC persistence - effects of aluminous clay and pedogenic Fe oxides}

Clay minerals and Fe oxides are considered as important mineral constituents fostering aggregation and subsequent OC storage via physical protection (Denef et al., 2004). The overwhelming portion of OC in the studied topsoils resided in mineral-organic associations $(35 \%-81 \%)$, whereas OC occluded in aggregates amounted to $7 \%-24 \%$, with a lower share under cropland than forest as determined by density fractionation (Kirsten et al., 2021). The low clay-high Fe cropland had an OC content more than twice larger than that of the low clay-low Fe cropland, but it comprised a significantly smaller MWD. Thus, a shift towards more macroaggregation, indicated by a larger MWD in certain mineralogical combinations, did not result in higher total OC storage, like shown for other tropical soils (Barthès et al., 2008; Bartoli et al., 1991; Spaccini et al., 2001). The OC content of the $>4 \mathrm{~mm}$ aggregate and $2-4 \mathrm{~mm}$ aggregate fractions accounted for $42 \%$ to $73 \%$ of the total soil OC content (Fig. 1b). This, however, does not per se indicate the relevance of macroaggregation for OC storage in weathered tropical soils like proposed by others (Feller and Beare, 1997; King et al., 2019; Six et al., 2002). The high clay-low Fe forest with the highest share in $>4$ and $2-4 \mathrm{~mm}$ aggregates had significantly lower OC contents in these fractions than most other mineralogical combinations. Comparing forest with cropland soils (Table 2), we observed significantly reduced OC contents in the majority of macroaggregate fractions of the low clay-low $\mathrm{Fe}$ and high clay-high $\mathrm{Fe}$ croplands, as reported in other studies (Blanco-Canqui and Lal, 2004; Lobe et al., 2011). In contrast, fewer changes of aggregateassociated and total soil OC contents were observed in the low clay-high Fe combination, despite the fact that it experienced the strongest disaggregation of the largest macroaggregates (Figs. 1a and 2). We conclude that larger amounts of $>2 \mathrm{~mm}$ aggregates or higher stability during wet sieving does not automatically translate into higher aggregateassociated OC contents, as reported for Ferralsols (Maltoni et al., 2017). Given all these observations and the fact that occluded OM determined by density fractionation was mostly of subordinate relevance, particularly in croplands, OC storage in study soils seems rather disconnected from their aggregation status. Consequently, the loss of large aggregates and the mass redistribution into smaller aggregate size fractions does not automatically imply a loss of soil OC, because a substantial part of the OC in aggregate fractions is bound to minerals with a higher persistence against land-use change (Kirsten et al., 2021). Here, density fractionation could shed more light on the nature and quantity of OM located in certain aggregate size fractions.

Microaggregates contained the highest OC content per unit of mass for almost all mineralogical combinations, depth increments, and land uses (Table 2). This is in line with the findings of Chenu and Plante (2006) and Lobe et al. (2011) that microaggregates can significantly contribute to OC storage. As aggregates were isolated by dry sieving, these microaggregates were not located inside larger aggregates, rendering them principally better accessible for OC allocation. Particularly, OC contained in the $<0.25 \mathrm{~mm}$ aggregates of the low clay-high Fe combination revealed a strong persis- 
tence against land-use change, which explains well the unaltered soil OC contents upon land-use change.

\section{Conclusions}

Classification of soils into mineralogical combinations of aluminous clay and pedogenic $\mathrm{Fe}$ oxides revealed significant effects of mineral constituents on soil structure and related OC storage in weathered tropical soils. Despite that, overall patterns across combinations were more similar than different, i.e., always comprising a high level of macroaggregation and aggregate stability. Aggregates $>4 \mathrm{~mm}$ of the low claylow $\mathrm{Fe}$ and high clay-high $\mathrm{Fe}$ combinations were less affected by land-use change; thus pedogenic $\mathrm{Fe}$ in a certain relation with aluminous clay ( 0.13 to 0.23 ) seems beneficial to maintain the structural integrity of macroaggregates. Despite the high physical stability, OC contents of macroaggregates declined substantially in most mineralogical combinations if forest was compared with cropland land use. This highlights the fact that structural integrity of macroaggregates during land-use change cannot be equated with OC persistence. For the low clay-high Fe combination, substantial destruction of $>4 \mathrm{~mm}$ aggregates during land-use change due to agricultural management was also not accompanied by higher OC losses. Hence, we must reject our initial hypothesis that the mineralogical combination that results in the greatest aggregate stability best preserves $\mathrm{OC}$ during the conversion from forest to cropland. Thus, the formation of macroaggregates cannot be considered as a main stabilization process for OC in strongly weathered soils of the humid tropics. We suggest that the formation of mineral-organic associations as part of the aggregate size fractions is the most important process that preserves OC during land-use change in these soils.

Data availability. The present study builds in part on the study by Kirsten et al. (2021, https://doi.org/10.1038/s41598-021-84777-7). Otherwise, all data to ensure the independent explanation of this study are included in Sects. 1 and 2.

Supplement. The supplement related to this article is available online at: https://doi.org/10.5194/soil-7-363-2021-supplement.

Author contributions. KK, RM, MK, and KHF designed the project. MK, KK, RM, DNK, and KHF collected soil or data to supported the sampling campaign. MK, KK, RM, and KHF evaluated data, and all authors conducted a thorough critical review of the manuscript. MK, KK, and RM wrote the manuscript with contributions of all authors.
Competing interests. The authors declare that they have no conflict of interest.

Disclaimer. Publisher's note: Copernicus Publications remains neutral with regard to jurisdictional claims in published maps and institutional affiliations.

Special issue statement. This article is part of the special issue "Tropical biogeochemistry of soils in the Congo Basin and the African Great Lakes region”. It is not associated with a conference.

Acknowledgements. We are grateful to the officials of Amani Nature Reserve who supported the field campaign in February 2018. Aloyce Mkongewa enthusiastically assisted fieldwork. We are also indebted to Gisela Ciesielski, Manuela Unger, Mandy Meise, Tobias Krause, Thomas Klinger, Gudrun Nemson-von Koch, and Christine Krenkewitz for laboratory support and analytical work. Finally, the authors would like to thank the two reviewers for their comprehensive reading of the manuscript and constructive suggestions for its improvement.

Financial support. This research has been supported by the Deutsche Forschungsgemeinschaft (grant nos. FE 504/15-1, KA 1737/16-1, and MI 1377/11-1).

This open-access publication was funded by the Technische Universität Dresden (TUD).

Review statement. This paper was edited by Sebastian Doetterl and reviewed by Jean-Thomas Cornelis and one anonymous referee.

\section{References}

Anda, M., Shamshuddin, J., Fauziah, C. I., and Omar, S. S.: Mineralogy and factors controlling charge development of three Oxisols developed from different parent materials, Geoderma, 143, 153-167, 2008.

Asano, M. and Wagai, R.: Evidence of aggregate hierarchy at microto submicron scales in an allophanic Andisol, Geoderma, 216, 62-74, 2014.

Barré, P., Fernandez-Ugalde, O., Virto, I., Velde, B., and Chenu, C.: Impact of phyllosilicate mineralogy on organic carbon stabilization in soils. Incomplete knowledge and exciting prospects, Geoderma, 235-236, 382-395, https://doi.org/10.1016/j.geoderma.2014.07.029, 2014.

Barthès, B. G., Kouakoua, E., Larré-Larrouy, M.-C., Razafimbelo, T. M., de Luca, Edgar F., Azontonde, A., Neves, C. S. V. J., de Freitas, Pedro L., and Feller, C. L.: Texture and sesquioxide effects on water-stable aggregates and organic matter in some tropical soils, Geoderma, 143, 14-25, 2008.

Bartoli, F., Burtin, G., and Herbillon, A. J.: Disaggregation and clay dispersion of Oxisols: Na resin, a recommended methodology, Geoderma, 49, 301-317, 1991. 
Bartoli, F., Philippy, R., and Burlin, G.: Influence of organic matter on aggregation in Oxisols rich in gibbsite or in goethite. I. Structures: the fractal approach, Geoderma, 54, 231-257, 1992.

Blanco-Canqui, H. and Lal, R.: Mechanisms of Carbon Sequestration in Soil Aggregates, CRC Cr. Rev. Plant Sci., 23, 481-504, 2004.

Bronick, C. J. and Lal, R.: Soil structure and management: a review, Geoderma, 124, 3-22, 2005.

Carter, M. R. and Gregorich, E. G. (Eds.): Soil sampling and methods of analysis. Canadian Society of Soil Science, CRC Press, Boca Raton, FL, USA, p. 1224, 2008.

Chaplot, V. and Cooper, M.: Soil aggregate stability to predict organic carbon outputs from soils, Geoderma, 243-244, 205-213, 2015.

Chaplot, V., Bouahom, B., and Valentin, C.: Soil organic carbon stocks in Laos: spatial variations and controlling factors, Glob. Change Biol., 16, 1380-1393, 2010.

Chenu, C. and Plante, A. F.: Clay-sized organo-mineral complexes in a cultivation chronosequence: revisiting the concept of the "primary organo-mineral complex", Eur. J. Soil Sci., 57, 596607, 2006.

Denef, K., Six, J., Merckx, R., and Paustian, K.: Short-term effects of biological and physical forces on aggregate formation in soils with different clay mineralogy, Plant Soil, 246, 185-200, 2002.

Denef, K., Six, J., Merckx, R., and Paustian, K.: Carbon Sequestration in Microaggregates of No-Tillage Soils with Different Clay Mineralogy, Soil Sci. Soc. Am. J., 68, 1935-1944, https://doi.org/10.2136/sssaj2004.1935, 2004.

Don, A., Schumacher, J., and Freibauer, A.: Impact of tropical landuse change on soil organic carbon stocks - a meta-analysis, Glob. Change Biol., 17, 1658-1670, 2011.

Duiker, S. W., Rhoton, F. E., Torrent, J., Smeck, N. E., and Lal, R.: Iron (Hydr)Oxide Crystallinity Effects on Soil Aggregation, Soil Sci. Soc. Am. J., 67, 606-611, https://doi.org/10.2136/sssaj2003.6060, 2003.

Dultz, S., Woche, S. K., Mikutta, R., Schrapel, M., and Guggenberger, G.: Size and charge constraints in microaggregation: Model experiments with mineral particle size fractions, Appl. Clay Sci., 170, 29-40, 2019.

Durn, G., Škapin, S. D., Vdoviæ, N., Rennert, T., Ottner, F., Ružièiæ, S., Cukrov, N., and Sondi, I.: Impact of iron oxides and soil organic matter on the surface physicochemical properties and aggregation of Terra Rossa and Calcocambisol subsoil horizons from Istria (Croatia), Catena, 183, 104184, https://doi.org/10.1016/j.catena.2019.104184, 2019.

FAO: Status of the World's Soil Resources: Main report, FAO, ITPS, Rome, XXXIX, 608, 2015.

Feller, C. and Beare, M. H.: Physical control of soil organic matter dynamics in the tropics, Geoderma, 79, 69-116, 1997.

Fernández-Ugalde, O., Barré, P., Hubert, F., Virto, I., Girardin, C., Ferrage, E., Caner, L., and Chenu, C.: Clay mineralogy differs qualitatively in aggregate-size classes: clay-mineral-based evidence for aggregate hierarchy in temperate soils, Eur. J. Soil Sci., 64, 410-422, 2013.

Gee, G. W. and Bauder, J. W.: Particle-size analysis, in: Methods of soil analysis: Part 1 Physical and mineralogical methods, edited by: Klute, A. and Page, A. L., 2nd Edn., no. 9, American Society of Agronomy, Soil Science Society of America, Madison, 383$412,1986$.
Gentile, R., Vanlauwe, B., Kavoo, A., Chivenge, P., and Six, J.: Residue quality and $\mathrm{N}$ fertilizer do not influence aggregate stabilization of $\mathrm{C}$ and $\mathrm{N}$ in two tropical soils with contrasting texture, Nutr. Cycl. Agroecosys., 88, 121-131, 2010.

Hamilton, A. C. and Bensted-Smith, R.: Forest Conservation in the East Usambara Mountains, Tanzania, IUCN - The World Conservation Union, Gland, Switzerland, 1989.

Hou, T., Xu, R., and Zhao, A.: Interaction between electric double layers of kaolinite and $\mathrm{Fe} / \mathrm{Al}$ oxides in suspensions, Colloid. Surface. A, 297, 91-94, 2007.

Igwe, C. A., Zarei, M., and Stahr, K.: Stability of aggregates of some weathered soils in south-eastern Nigeria in relation to their geochemical properties, J. Earth Syst. Sci., 122, 1283-1294, 2013.

Kaiser, K. and Guggenberger, G.: Mineral surfaces and soil organic matter, Eur. J. Soil Sci., 54, 219-236, 2003.

Kamamia, A. W., Vogel, C., Mwangi, H. M., Feger, K.H., and Julich, S.: Mapping soil aggregate stability using digital soil mapping: A case study of Ruiru reservoir catchment, Kenya, Geoderma Regional, 24, e00355, https://doi.org/10.1016/j.geodrs.2020.e00355, 2021.

King, A. E., Congreves, K. A., Deen, B., Dunfield, K. E., Voroney, R. P., and Wagner-Riddle, C.: Quantifying the relationships between soil fraction mass, fraction carbon, and total soil carbon to assess mechanisms of physical protection. Soil Biol. Biochem., 135, 95-107, 2019.

Kirsten, M., Kimaro, D. N., Feger, K.-H., and Kalbitz, K.: Impact of land use on soil organic carbon stocks in the humid tropics of NE Tanzania, J. Plant Nutr. Soil Sci., 182, 625-636, 2019.

Kirsten, M., Mikutta, R., Vogel, C., Thompson, A., Mueller, C. W., Kimaro, D. N., Bergsma, H. L. T., Feger, K.-H., and Kalbitz, $\mathrm{K}$.: Iron oxides and aluminous clays selectively control soil carbon storage and stability in the humid tropics, Sci. Rep.-UK, 11, 5076, https://doi.org/10.1038/s41598-021-84777-7, 2021.

Kleber, M., Eusterhues, K., Keiluweit, M., Mikutta, C., Mikutta, R., and Nico, P. S.: Mineral-Organic Associations: Formation, Properties, and Relevance in Soil Environments, Adv. Agron., 130, 1-140, 2015.

Kravchenko, A. N., Negassa, W. C., Guber, A. K., and Rivers, M. L.: Protection of soil carbon within macro-aggregates depends on intra-aggregate pore characteristics, Sci. Rep.-UK, 5, 16261, https://doi.org/10.1038/srep16261, 2015.

Larney, F. J.: Dry-Aggregate Size Distribution, in: Soil sampling and methods of analysis, edited by: Carter, M. R. and Gregorich, E. G., 2nd Edn., Canadian Society of Soil Science, CRC Press, Boca Raton, FL, USA, 821-831, 2008.

Le Bissonnais, Y.: Aggregate stability and assessment of soil crustability and erodibility: I. Theory and methodology, Eur. J. Soil Sci., 47, 425-437, 1996.

Le Bissonnais, Y., Prieto, I., Roumet, C., Nespoulous, J., Metayer, J., Huon, S., Villatoro, M., and Stokes, A.: Soil aggregate stability in Mediterranean and tropical agro-ecosystems: effect of plant roots and soil characteristics, Plant Soil, 424, 303-317, 2018.

Lobe, I., Sandhage-Hofmann, A., Brodowski, S., du Preez, C. C., and Amelung, W.: Aggregate dynamics and associated soil organic matter contents as influenced by prolonged arable cropping in the South African Highveld, Geoderma, 162, 251-259, 2011.

Maltoni, K. L., de Mello, L. M. M., and Dubbin, W. E.: The effect of Ferralsol mineralogy on the distribution of organic $\mathrm{C}$ across 
aggregate size fractions under native vegetation and no-tillage agriculture, Soil Use Manage., 33, 328-338, 2017.

Marín-Spiotta, E., Swanston, C. W., Torn, M. S., Silver, W. L., and Burton, S. D.: Chemical and mineral control of soil carbon turnover in abandoned tropical pastures, Geoderma, 143, 49-62, 2008.

Mehra, O. P. and Jackson, M. L.: Iron Oxide Removal from Soils and Clays by a Dithionite-Citrate System Buffered with Sodium Bicarbonate, Clays Clay. Miner., 7, 317-327, 1958.

Mujuru, L., Mureva, A., Velthorst, E. J., and Hoosbeek, M. R.: Land use and management effects on soil organic matter fractions in Rhodic Ferralsols and Haplic Arenosols in Bindura and Shamva districts of Zimbabwe, Geoderma, 209-210, 262-272, 2013.

Paul, S., Flessa, H., Veldkamp, E., and López-Ulloa, M.: Stabilization of recent soil carbon in the humid tropics following land use changes: Evidence from aggregate fractionation and stable isotope analyses, Biogeochemistry, 87, 247-263, 2008.

Peng, X., Yan, X., Zhou, H., Zhang, Y. Z., and Sun, H.: Assessing the contributions of sesquioxides and soil organic matter to aggregation in an Ultisol under long-term fertilization, Soil Till. Res., 146, 89-98, 2015.

Qafoku, N. P. and Sumner, M. E.: Adsorption and Desorption of Indifferent Ions in Variable Charge Subsoils, Soil Sci. Soc. Am. J., 66, 1231-1239, 2002.

Rabbi, S. M. F., Wilson, B. R., Lockwood, P. V., Daniel, H., and Young, I. M.: Aggregate hierarchy and carbon mineralization in two Oxisols of New South Wales, Australia, Soil Till. Res., 146, 193-203, 2015.

Schmidt, M. W. I., Torn, M. S., Abiven, S., Dittmar, T., Guggenberger, G., Janssens, I. A., Kleber, M., Kögel-Knabner, I., Lehmann, J., Manning, David A C, Nannipieri, P., Rasse, D. P., Weiner, S., and Trumbore, S. E.: Persistence of soil organic matter as an ecosystem property, Nature, 478, 49-56, 2011.

Schwertmann, U.: Differenzierung der Eisenoxide des Bodens durch Extraktion mit Ammoniumoxalat-Lösung, Z. Pflanzenernaehr. Dueng. Bodenk., 105, 194-202, 1964.

Six, J., Elliott, E. T., and Paustian, K.: Soil macroaggregate turnover and microaggregate formation: A mechanism for $\mathrm{C}$ sequestration under no-tillage agriculture, Soil Biol. Biochem., 32, 2099-2103, 2000a.
Six, J., Paustian, K., Elliott, E. T., and Combrink, C.: Soil Structure and Organic Matter, Soil Sci. Soc. Am. J., 64, 681-689, https://doi.org/10.2136/sssaj2000.642681x, 2000b.

Six, J., Feller, C., Denef, K., Ogle, S. M., de Moraes, J. C., and Albrecht, A.: Soil organic matter, biota and aggregation in temperate and tropical soils - Effects of no-tillage, Agronomie, 22, 755-775, 2002.

Six, J., Bossuyt, H., Degryze, S., and Denef, K.: A history of research on the link between (micro)aggregates, soil biota, and soil organic matter dynamics, Soil Till. Res., 79, 7-31, 2004.

Spaccini, R., Zena, A., Igwe, C. A., Mbagwu, J. S. C., and Piccolo, A.: Carbohydrates in water-stable aggregates and particle size fractions of forested and cultivated soils in two contrasting tropical ecosystems, Biogeochemistry, 53, 1-22, 2001.

Tisdall, J. M. and Oades, J. M.: Organic matter and water-stable aggregates in soils, J. Soil Sci., 33, 141-163, 1982.

Totsche, K. U., Amelung, W., Gerzabek, M. H., Guggenberger, G., Klumpp, E., Knief, C., Lehndorff, E., Mikutta, R., Peth, S., Prechtel, A., Ray, N., and Kögel-Knabner, I.: Microaggregates in soils, J. Plant Nutr. Soil Sc., 181, 104-136, 2018.

Trüby, P. and Aldinger, E.: Eine Methode zur Bestimmung austauschbarer Kationen in Waldböden, Z. Pflanzenernaehr. Bodenk., 152, 301-306, 1989.

Vrdoljak, G. and Sposito, G.: Soil aggregate hierarchy in a Brazilian oxisol, in Soil Mineral-Organic Matter-Microorganism Interactions and Ecosystem Health, Dynamics, Mobility and Transformation of Pollutants and Nutrients, Developments in Soil Science, Elsevier, 197-217, 2002.

Wagai, R. and Mayer, L. M.: Sorptive stabilization of organic matter in soils by hydrous iron oxides, Geochim. Cosmochim. Ac., 71, 25-35, https://doi.org/10.1016/j.gca.2006.08.047, 2007.

West, S. L., White, G. N., Deng, Y., McInnes, K. J., Juo, A. S. R., and Dixon, J. B.: Kaolinite, halloysite, and iron oxide influence on physical behavior of formulated soils, Soil Sci. Soc. Am. J., 68, 1452-1460, 2004.

Youker, R. E. and McGuinness, J. L.: A short method of obtaining mean weight-diameter values of aggregate analyses of soil, J. Soil Sci., 83, 291-294, 1957. 